ISSN: 2527-1075

\title{
ESFIRRA DE GOMA DE TAPIOCA E BATATA COM CASCA RECHEADA COM TAMBAQUI
}

\section{TAPIOCA RUBBER AND POTATO WITH BARK SCRAP CUTTING WITH TAMBAQUI}

R. R. SOUZA ${ }^{1}$; T. D. S. RODRIGUES ${ }^{1}$; T. W. OLIVEIRA ${ }^{1}$; P. R. S. BORGES ${ }^{1}$; I. H. V. S. SANTOS $^{1}$

${ }^{1}$ Centro Universitário São Lucas, Porto Velho-RO

E-mail: paulo.borges@saolucas.edu.br

\begin{abstract}
article info
Article history:

Received 12 May 2017

Accepted 3 August 2017

Available online 20 September 2017

\author{
PALAVRAS-CHAVE: Produto amazônico; Aproveitamento integral; Peixe; Rotulagem \\ nutricional.
}

KEYWORDS: Amazonian product; Integral use; Fish; Nutrition labeling.

RESUMO: O consumo de salgados fritos ou assados faz parte do hábito brasileiro, constituem-se alimentos baratos e de fácil acesso. Este trabalho teve como objetivo desenvolver uma esfirra assada de goma de tapioca e batata inglesa com recheio de tambaqui para indivíduos saudáveis, além de analisar a qualidade nutricional deste produto por meio da elaboração do rótulo nutricional. Para a determinação dos Valores Diários de Referência (VD\%), utilizaram-se legislações $R D C n^{\circ} 359, R D C n^{\circ} 360$ e RDC $n^{\circ} 54$ sendo esta última para apontar as fontes de nutrientes não contemplados no rótulo nutricional obrigatório. O produto deste estudo é uma opção de alimento com alto teor de proteínas advindo do peixe, alimento consumido em larga escala na região norte, com um recheio de requeijão caseiro, sendo uma boa opção de lanche nutritivo.
\end{abstract}

\begin{abstract}
The consumption of fried or roasted salted is part of the Brazilian habit, constitute cheap food and easy access. The objective of this work was to develop a roasted sausage of tapioca gum and potato with tambaqui filling for healthy individuals, besides analyzing the nutritional quality of this product through the elaboration of the nutritional label. $R D C n^{\circ} 359, R D C n^{\circ} 360$ and $R D C n^{\circ} 54$ were used to determine the Daily Values of Reference (VD\%), the latter being to indicate the sources of nutrients not included in the obligatory nutritional label. The product of this study is a food option with high protein content from fish, food consumed in a large scale in the northern region, with a filling of homemade curd, being a good option of nutritious snack.
\end{abstract}

\section{INTRODUÇÃO}

Os salgados fritos ou assados são considerados alimentos de baixo custo, fácil preparo e boa aceitabilidade pela população (PESSANHA \& FERREIRA, 2010). Salgados são alimentos servidos como pequenos lanches, possuem diversos tipos de recheio e apresentam opções fritas e assadas. Dentre os fritos podemos destacar os bolinhos de carne, coxinha, croquete, quibe, rissole e saltenha e dentre os salgados assados têm-se empada, esfirra e saltenha (ABIMAQ, 2015). Possuem um alto teor lipídico por utilizarem margarina e óleo em 


\section{The Journal of Engineering and Exact Sciences - \\ JCEC \\ ISSN: 2527-1075}

grandes quantidades e são facilmente encontrados em festas ou como substituto de refeições em lanchonetes.

A goma de tapioca é um alimento natural, livre de glúten e de gordura, que possui reduzido teor de sódio, sendo uma boa fonte de carboidratos, razões pelas quais se torna uma boa opção para introduzir em receitas utilizando-a parcialmente com a farinha de trigo (MELO et al. 2016).

O aproveitamento total dos alimentos é a utilização de um determinado alimento na sua totalidade. A falta de informações sobre os princípios nutritivos de cascas leva a população a jogar estas partes no lixo, gerando o desperdício de toneladas de recursos alimentares (OLIVEIRA et al. 2002). A batata inglesa (Solanum tuberosum L.) é considerada um dos alimentos mais nutritivos para o homem, contendo em sua composição carboidratos, proteínas de alta qualidade, além de vitaminas e sais minerais. A casca da batata é fonte de fibra, ferro, cálcio, potássio, fósforo, zinco e vitamina $\mathrm{B}$, no entanto, quando descascada perde grande parte de seu potencial nutritivo e se transforma em alimento de alto índice glicêmico, devido à perda das fibras e ao desequilíbrio resultante entre o teor de carboidratos e de proteínas (FERNANDES, 2006).

O consumo de peixes teve uma expansão após o conhecimento das suas qualidades nutricionais, que evidenciou as vantagens do peixe enquanto alimento, principalmente pela alta quantidade de vitaminas A, D, proteínas e lipídeos de qualidade (FIB, 2009). O tambaqui (Colossoma macropomum) é um peixe muito encontrado na América do Sul como peixe de cultivo, principalmente na região norte, onde é consumido em larga escala. Por ser uma espécie de fácil adaptação, é facilmente encontrado nas regiões Norte e Nordeste (SILVA et al. 2013).

Diante disto, este trabalho teve como objetivo desenvolver e analisar o rótulo nutricional de uma esfirra fechada, assada, com massa à base de goma de tapioca e batata inglesa utilizada integralmente, recheada com tambaqui e um requeijão caseiro com foco no público composto por indivíduos saudáveis.

\section{MATERIAL E MÉTODOS}

Todo o experimento de elaboração do produto foi realizado no Laboratório de Práticas Dietéticas do Centro Universitário São Lucas - LPD/UNISL, situado no município de Porto Velho/RO. Com base em uma receita tradicional de esfirra, desenvolveu-se uma esfirra com massa à base de goma de tapioca e batata inglesa com casca e recheio de tambaqui e requeijão caseiro.

Para a elaboração da Ficha Técnica de Preparo - FTP do produto, todos os ingredientes foram separados e mensurados em medidas caseiras e convertidos em $\mathrm{g}$ (Tabela 1) por meio de balança digital da marca Toledo®, com capacidade máxima de $15 \mathrm{~kg}$. 


\section{The Journal of Engineering and Exact Sciences - \\ JCEC \\ ISSN: 2527-1075}

Tabela 1 - Peso líquido dos ingredientes utilizados na elaboração da esfirra de goma de tapioca com batata inglesa e do recheio de tambaqui

\begin{tabular}{lccc}
\hline Ingredientes - Massa & Quantidade & $\begin{array}{c}\text { Ingredientes }- \\
\text { recheio }\end{array}$ & Quantidade \\
\hline $\begin{array}{l}\text { Leite } \\
\text { Batata inglesa com } \\
\text { casca }\end{array}$ & $200 \mathrm{~mL}$ & Tambaqui & $195 \mathrm{~g}$ \\
Goma de tapioca & $125 \mathrm{~g}$ & Tomate & $172 \mathrm{~g}$ \\
Farinha de trigo & $95 \mathrm{~g}$ & Cebola & $100 \mathrm{~g}$ \\
Sal & $95 \mathrm{~g}$ & Creme de leite & $150 \mathrm{~g}$ \\
Fermento biológico & $5 \mathrm{~g}$ & Suco de limão & $10 \mathrm{ml}$ \\
Açucar & $15 \mathrm{~g}$ & Amido de milho & $30 \mathrm{~g}$ \\
& $12 \mathrm{~g}$ & Sal & $12 \mathrm{~g}$ \\
\hline
\end{tabular}

A formulação da esfirra foi elaborada em etapas distintas conforme descrito a seguir:

Preparo da massa:

Lavou-se em água corrente as batatas com casca, que foram coccionadas por $20 \mathrm{~min}$ em uma panela de pressão doméstica. Depois de fria as batatas foram processadas integralmente em um processador da marca Black \& Decker ${ }^{\circledR}$. Posteriomente, a mistura formada foi despejada em um recipiente plástico e misturada com os demais ingredientes até a massa desgrudar das mãos. A massa foi dividida em bolas e reservada por 20 min para crescer.

Preparo do recheio:

Para o preparo do requeijão caseiro, adicionou-se em uma panela o creme de leite, o amido de milho e sal e mexeu-se até obter a consitência cremosa e aveludada.

Para o preparo do molho de peixe, adicionou-se ao filé de tambaqui sal e limão e deixou descansar por $10 \mathrm{~min}$ sob refrigeração e assou-se em forno doméstico convencional pré aquecido a $200{ }^{\circ} \mathrm{C}$ por $40 \mathrm{~min}$. Após assado e frio o peixe foi desfiado e refogado em um molho feito com cebola, tomate e cebolinha. Após o molho pronto, adiconou-se o requeijão caseiro.

Montagem das esfirras

Depois da massa crescida, abriu-se utilizando um rolo e retirou-se a porção com um copo de tamanho médio. Recheou-se e modelou-se no formato característico. Após a modelagem, as esfirras foram assadas por $40 \mathrm{~min}$ em forno doméstico convencional pré aquecido a $200{ }^{\circ} \mathrm{C}$. Depois de assadas, foram pesadas, rendendo cinco porções de $100 \mathrm{~g}$ cada (três unidades pequenas) conforme porção determinada pela RDC n³60 (BRASIL, 2003).

Com os dados obtidos na FTP foi elaborado o rótulo nutricional do produto. Para a determinação dos Valores Diários de Referência (VD\%) do rótulo nutricional, foram 


\section{The Journal of Engineering and Exact Sciences - \\ JCEC \\ ISSN: 2527-1075}

utilizadas as legislações RDC n 359 e 360 (ANVISA, 2003) e RDC no 54 (ANVISA, 2012) apontando fontes de nutrientes não contemplados no rótulo nutricional obrigatório. Para o cálculo dos macros e micronutrientes foram utilizadas as tabelas TACO (NEPA, 2011), Tabela de Composição de Alimentos da Amazônia (AGUIAR, 1996) e Storck et al. (2013).

\section{RESULTADOS E DISCUSSÃO}

Obteve-se os seguintes resultados de informação nutricional da esfirra elaborada no presente estudo (Tabela 2).

Nas informações nutricionais (Tabela 2), destaca-se a quantidade de carboidratos, proveniente da goma de tapioca, farinha de trigo e batata inglesa. Os carboidratos compõem a maior parte da matéria viva no planeta Terra, constituindo, portanto, a maior parte da alimentação humana: 55\% a 75\% do valor energético total (VET) devem ser fornecidos pelo grupo dos carboidratos (BRASIL, 2014). Além disso, possuem ação poupadora de energia, ou seja, a presença de carboidratos suficientes para satisfazer a demanda energética impede que as proteínas sejam desviadas para essa proposta, permitindo que a maior proporção de proteínas seja usada para a função básica de construção de tecido (ALMEIDA et al., 2013).

Tabela 2 - Rótulo nutricional da esfirra de goma de tapioca e batata inglesa com recheio de tambaqui

\begin{tabular}{lcc}
\hline & $\mathbf{1 0 0} \mathbf{g}$ (três unidades) & VD (\%)* \\
\hline Valor energético & $334 \mathrm{Kcal}=1068 \mathrm{~kJ}$ & $16 \%$ \\
Carboidratos(g) & $48 \mathrm{~g}$ & $16 \%$ \\
Proteinas $(\mathrm{g})$ & $14 \mathrm{~g}$ & $18 \%$ \\
Gorduras totais $(\mathrm{g})$ & $9,6 \mathrm{~g}$ & $17 \%$ \\
Gorduras saturadas $(\mathrm{g})$ & $4 \mathrm{~g}$ & $20 \%$ \\
Gorduras trans $(\mathrm{g})$ & $* *$ & $* *$ \\
Fibra alimentar $(\mathrm{g})$ & $2 \mathrm{~g}$ & $8 \%$ \\
Sódio $(\mathrm{mg})$ & $233 \mathrm{mg}$ & $10 \%$ \\
\hline
\end{tabular}

*Valores diários de referência com base em uma dieta de $2000 \mathrm{kcal}$ ou 8400kJ. Seus valores diários podem ser maiores ou menores dependendo de suas necessidades energéticas. ** valores não determinados.

Outro destaque é a quantidade de proteínas, o produto desenvolvido apresenta $14 \mathrm{~g}$ sendo considerada um alimento com alto teor de proteína, visto que RDC $\mathrm{n}^{\circ} 54$ (ANVISA, 2012), define o mínimo de $12 \mathrm{~g}$ em uma porção de $100 \mathrm{~g}$. Tal resultado foi possível devido ao peixe tambaqui que foi utilizado para o recheio que possui $24,8 \mathrm{~g}$ de proteínas em $100 \mathrm{~g}$ de filé (AGUIAR, 1996). Os peixes são boas fontes de todos os aminoácidos essenciais, substâncias químicas que compõem as proteínas necessárias para o crescimento e a manutenção do corpo humano, também são fontes importantes de ferro de alta biodisponibilidade e vitamina B12, além de serem boas fontes de cálcio e ácidos graxos essenciais (BRASIL, 2008). 


\section{The Journal of Engineering and Exact Sciences - \\ JCEC}

ISSN: 2527-1075

As gorduras totais na esfirra de goma de tapioca e batata inglesa com recheio de tambaqui apresentaram 9,6 g, representando 17\% do Valor Diário de Referência, devido à adição do creme de leite utilizado na preparação do requeijão que compõe o recheio. Dreizler \& Ehemann (2012) enfatizam que o forno por elevar os alimentos em altas temperaturas proporciona diminuição da quantidade de gorduras no alimento em relação ao processo de fritura, pois no forneamento parte da gordura sai do alimento ficando no recipiente enquanto no processo de fritura a gordura se incorpora ao alimento. Em contrapartida, Sizwr \& Whitney (2003), ressaltam que as gorduras são ocultadas quando os alimentos são fritos ou assados. O Ministério da Saúde recomenda a substituição de alimentos fritos, para alimentos assados, por diminuir a quantidade de gorduras dos alimentos (BRASIL, 2008).

\section{CONCLUSÕES}

É possível produzir esfirras reduzindo a quantidade de farinha de trigo à massa, fazendo com que haja um aumento de carboidratos complexos na composição do produto. Este produto é mais uma opção de preparo com peixe, alimento consumido em larga escala na região norte e com alto teor de proteínas.

\section{AGRADECIMENTOS}

Ao Programa de Apoio a Pesquisa - PAP do Centro Universitário São Lucas, pelo apoio financeiro.

\section{REFERÊNCIAS}

ABIMAQ - ASSOCIAÇÃO BRASILEIRA DA INDÚSTRIA DE MÁQUINAS E EQUIPAMENTOS - Solução Técnica: Salgado frito e assado. Disponível em: $<$ http://www.datamaq.org.br/sebrae/Article.aspx?entityId=38297092-7a2f-de11-b521$0003 \mathrm{ffd} 062 \mathrm{a} 1>$ Acesso em: 25 de abril de 2015.

AGUIAR, J. P. L. Tabela de composição de alimentos da Amazônia. Acta Amazônica, n. 26, v.1/2, p. 121-126. 1996.

ALMEIDA, E. C.; LIMA, M. F.; FRANCO, R. C.; ZOLLAR, V.; BENETTI, G. B. Curso didático de Nutrição. $1^{\circ}$ edição, Ed. Yendis. São Caetano do Sul- SP, 2013.

ANVISA - AGÊNCIA NACIONAL DE VIGILÂNCIA SANITÁRIA BRASIL. RDC $\mathbf{n}^{\mathbf{0}} \mathbf{5 4}$, de 12 de novembro de 2012. Regulamento Técnico Mercosul sobre Informação Nutricional Complementar (declarações de propriedades nutricionais). Brasília: Ministério da Saúde, ANVISA, 2012.

ANVISA - AGÊNCIA NACIONAL DE VIGILÂNCIA5 SANITÁRIA BRASIL. RDC $\mathbf{n}^{\mathbf{o}}$ 359, de 23 de dezembro de 2003. Regulamento técnico de porções de alimentos embalados para fins de rotulagem nutricional. Brasília: Ministério da Saúde, ANVISA, 2003.

ANVISA. AGÊNCIA NACIONAL DE VIGILÂNCIA SANITÁRIA, BRASIL. RDC n⿳ 360, de 23 de dezembro de 2003. Regulamento técnico de porções de alimentos embalados para fins de rotulagem nutricional. Brasília: Ministério da Saúde, ANVISA, 2003. 
BRASIL. Ministério da Saúde. Guia alimentar para a população brasileira. 2. ed. Brasília: Ministério da Saúde, 2014.

DREIZLER, C.; EHEMANN, M. E. Comece hoje a perder peso. Editora: Vida Melhor. p. 66-69. Rio Janeiro, 2012.

FERNANDES, A. F. Utilização da farinha de casca de batata inglesa (Solanum tuberosum L.) na elaboração de pão integral. 2006. 127 p. Dissertação (Mestrado em Ciência dos Alimentos) - Universidade Federal de Lavras, Lavras, 2006.

FIB - FOOD INGREDIENTS BRASIL. Proteínas do peixe: propriedades funcionais das proteínas do peixe. Revista Food Ingredients Brasil n. 8, 2009. Disponível em: < http://www.revista-fi.com/materias/100.pdf $>$

MELO, L. R. C.; CASTRO, A. O.; SILVA, F. D. R.; TAVARES, M. F.; PATROCÍNIO, K. R. A.; Tapioca na mesa dos brasileiros. XXIII Prêmio Expocom 2016 - Exposição da Pesquisa Experimental em Comunicação, 2016.

NÚCLEO DE ESTUDOS E PESQUISA EM ALIMENTOS - NEPA. Tabela brasileira de composição de alimentos - TACO/NEPA - UNICAMP. - 4.ed. revisada e ampliada. - Campinas: UNICAMP, 2011.

OLIVEIRA, L. F. NASCIMENTO, M. R. F.; BORGES, S. VI.; RIBEIRO, P. C. N.; RUBACK, V. R. Aproveitamento alternativo da Casca do Maracujá amarelo para produção de Doce em calda. Revista de Ciência de Tecnologia de Alimentos, v. 22, n. 3 p.259-263, set./dez. 2002.

PESSANHA, T. M. T.; FERREIRA, K. S. Lipídios totais e perfil de ácidos graxos de "salgadinhos" comercializados em campos dos Goitacazes, RJ. Revista Alimento e Nutrição, v. 21, n. 3, p. 357-365, 2010.

SILVA, A. D. R.; SANTOS, R. B.; BRUNO, A. M. S. S.; SOARES, E. C. Cultivo de tambaqui em canais de abastecimento sob diferentes densidades de peixes. Acta Amazônica, v.43, n.4, 2013.

SIZER, F.S; WHITNEY, E. Nutrição: Conceitos e controvérsias. $8^{\circ}$ edição. Editora: Manole, Barueri. São Paulo, 2003

STORCKI, C. R.; NUNES, G. L.; OLIVEIRA, B. B.; BASSO, C. Folhas, talos, cascas e sementes de vegetais: composição nutricional, aproveitamento na alimentação e análise sensorial de preparações. Ciência Rural, v.43, n.3, p.537-543, mar, 2013. 